\title{
Secondary Occult Hepatitis C Virus Infection (HCV) in Chronic HCV Patients after Treatment with Sofosbuvir and Daclatasvir
}

\author{
Nashwa A. Abu Khadr ${ }^{1}$, Hanan H. Nouh ${ }^{2}$, Nesrine F. Hanafi ${ }^{1}$, \\ Sara L. Asser ${ }^{1}$ and Yousra A. Hussain ${ }^{1 *}$
}

${ }^{1}$ Department of Microbiology, Faculty of Medicine, Alexandria University, Alexandria, Egypt

${ }^{2}$ Department of Internal Medicine, Gastroenterology unit, Faculty of Medicine, Alexandria University, Alexandria, Egypt

*Corresponding author

\section{A B S T R A C T}

Keywords

Occult HCV, Peripheral

blood mononuclear

cells, Sofosbuvir,

Daclatasvir, Direct

acting antiviral drugs

Article Info

Accepted:

12 December 2017

Available Online:

10 January 2018
This study is a cross-sectional study aimed to assess the rate of occurrence of secondary occult hepatitis $\mathrm{C}$ virus ( $\mathrm{HCV}$ ) infection in patients treated with the combination of sofosbuvir and daclatasvir. This study included 40 patients whose serum turned negative for HCV ribonucleic acid (HCV RNA) via real time polymerase chain reaction (RT-PCR) after 3 months of the treatment. Blood samples on EDTA were collected from the patients to detect HCV RNA in peripheral blood mononuclear cells (PBMCs). At the end of the study there were 30 PBMCs HCV RNA negative patients and 10 PBMCs HCV RNA positive patients. Our data revealed the occurrence of secondary occult HCV infection in about $25 \%$ of $\mathrm{HCV}$ patients treated with the combination of sofosbuvir and daclatasvir.

\section{Introduction}

Hepatitis $\mathrm{C}$ virus (HCV) is the main cause of chronic liver disease all over the world. HCV affects about 200 million people worldwide. About 350000 deaths per yearare due to $\mathrm{HCV}$ infection. $\mathrm{HCV}$ is classified as a member of Flaviviridae family and Hepacivirus genus. $30 \%$ of infected people resolve their acute infection spontaneously, while about $70 \%$ turned to chronic $\mathrm{HCV}$ infection (Zaltron et al., 2012). Chronic HCV infection is detected by the persistence of $\mathrm{HCV}$ ribonucleic acid
(RNA) in the blood for 6 months or more after the onset of acute infection. Many factors can affect the degree of HCV chronicity such as the age at onset of the disease, gender, ethnicity, and jaundice during the acute infection (Chen et al., 2006).

Occult HCV infection (OCI) is identified by the presence of HCV RNA in the liver cells or peripheral blood mononuclear cells (PBMCs) of the patients whose serum samples test negative for HCV RNA by polymerase chain reaction (PCR) assays, with or without 
presence of HCV antibodies (Carreno et al., 2006).

OCI can lead to liver cirrhosis and hepatocellular carcinoma (Zaltron et al., 2012). PBMCs might be considered as a longlived $\mathrm{HCV}$ reservoir due to the persistence of viral RNA in the of patients who had cleared their viremia either spontaneously or after antiviral therapy. HCV RNA can be detected in PBMCs instead of liver biopsy in about $70 \%$ of patients with an OCI (Carreno et al., 2004).

OCI can be found in some high-risk people like hemodialysis and kidney transplanted patients, cryptogenic liver disease, and immune-deficient patients. But also, some data have been reported about the presence of OCI among healthy people without any liver disease. HCV genotypes 1 and 4 are the most genotypes involved in the OCI (Carreno et al., 2012; Youssef et al., 2012).

OCI has been defined in two different forms: cryptogenic and secondary. Cryptogenic OCI: if the patient has no anti-HCV antibodies but has elevated liver enzymes (Castillo et al., 2004). Secondary OCI: if the patient has antiHCV antibodies, has normal liver enzymes and had cleared his HCV infection neither spontaneously or after anti HCV therapy (Pham et al., 2004).

In the last few years, the combination of pegylated interferon (PEG-IFN) and ribavirin (RBV) was the only available treatment option for $\mathrm{HCV}$ genotype 4 (HCV-4) infection. But later on another treatment options are available such as direct acting antivirals (DAAs) which can used with or without addition of PEG-IFN/RBV. Now, combinations of DAAs are commonly used for the treatment of $\mathrm{HCV}-4$ infection due to higher cure rates, shorter treatment period, a higher genetic barrier, and minimal adverse events (AEs). One of the most effective and commonly used combinations of (DAAs) for the treatment of $\mathrm{HCV}-4$ is the combination of sofosbuvir (SOF) and daclatasvir (DCV) for 3 months (Abdel-Razek et al., 2015). DCV is $\mathrm{HCV}$ nonstructural protein NS5Ainhibitor (Yang et al., 2016), while SOF is a nucleotide analogue inhibitor (Bertino et al., 2016).

Results from clinical studies as well as preliminary real-life data showed that the combination of sofosbuvir and daclatasvir, is one of the most successful antiviral therapies with once-daily oral dosing, a low pill burden, good tolerability, limited drug-drug interactions, and also high (90\%) sustained virologic response rates. Such a combination has high pangenotypic antiviral potency (Pol et al., 2016).

\section{Materials and Methods}

\section{Study design}

Cross-sectional interventional study.

\section{Subjects}

All subjects included in this study were obtained from outpatient clinic of Alexandria Main University Hospital.

Institutional ethical board approval was taken prior to the study, as well as informed consent was taken from all the participants. A total of 40 adult $\mathrm{HCV}$ patients were included in this study (above 18 years of age).

Inclusion criteria were chronic $\mathrm{HCV}$ infection and treatment by combination of sofosbuvir (SOF) and daclatasvir (DCV) for three months which suitable for all grades of HCV infection (according to Child Pugh scoring). Exclusion criteria were co-infection with hepatitis B virus (HBV) or human immunodeficiency virus (HIV), schistosomiasis, diabetes 
mellitus, hepatotoxic drugs for example methotrexate, alcohol intake and history of hepatocellular carcinoma (HCC).

All the subjects included in the study were subjected for full history taking and clinical examination, Complete blood count, virological profile: $\mathrm{HCV}$ Abs, the surface antigen of hepatitis B virus (HBsAg), all liver function tests especially serum glutamateoxaloacetate transaminase (SGOT), serum glutamate-pyruvate transaminase (SGPT), Alkaline phosphatase, Serum bilirubin (direct and indirect), Serum albumin and Serum prothrombin, tumour marker: $\alpha$ feto protein, thyroid function test: thyroid stimulating hormone (TSH), abdominal ultrasonography to assess state of liver cirrhosis and portal hypertension and upper endoscopy to assess presence of oesophageal and gastric varices and manifestation of portal hypertensive gastropathy.

Serum samples will be collected to detect HCV RNA via real time polymerase chain reaction (RT-PCR) from patients: at the diagnosis and the start of the treatment, after one month of the treatment and after three months of the treatment (at the end of the treatment).

Blood samples on EDTA will be collected from all patients whose serum PCR will turn negative for HCV RNA after one month (early virological response) and those who will turn negative after three months of treatment to detect HCV RNA in PBMCs.

\section{Isolation of serum and PBMC}

Serum was separated from whole blood in 2Eppendorf tubes following centrifugation. Isolated serum was immediately stored at $20^{\circ} \mathrm{C}$ in order to avoid repeat freeze thawing.

Peripheral blood lymphocytes were isolated immediately following blood drawing $(5.0 \mathrm{ml})$ from serum-negative patients. Whole blood was layered over Ficoll-Hypaque (Sigma, USA) density- gradient medium.

\section{HCV RNA quantification}

The COBAS AmpliPrepTaqman analyser (CAP-CTM) instrument / COBAS TaqMan Real time PCR HCV Test kit (Roche Molecular Systems, Mannheim, Germany) was used for quantification of viral loads according to the manufacturer's instructions (Fusun et al., 2013).

\section{Statistical analyses}

Data were fed to the computer and analyzed using IBM SPSS software package version 20.0. (Armonk, NY: IBM Corp).Qualitative data were described using number and percent. The Kolmogorov-Smirnov test was used to verify the normality of distribution Quantitative data were described using range (minimum and maximum), mean, standard deviation and median. Significance of the obtained results was judged at the 5\% level (Kotz et al., 2006; Kirkpatrick et al., 2013).

\section{The used tests were}

\section{Chi-square test}

For categorical variables, to compare between different groups

\section{Fisher's Exact or Monte Carlo correction}

Correction for chi-square when more than $20 \%$ of the cells have expected count less than 5

\section{Student t-test}

For normally distributed quantitative variables, to compare between two studied groups. 


\section{Mann Whitney test}

For abnormally distributed quantitative variables, to compare between two studied groups

\section{Results and Discussion}

This study comprised two groups HCV RNA PBMCs negative patients and HCV RNA PBMCs positive patients.

There were no statistical significant differences between the two groups regarding age $(p=0.244)$, gender $(p=0.269)$, presence of risky occupation $(\mathrm{p}=1.000)$, and mode of transmission $(\mathrm{p}=1.000)$. There were no statistical significant differences between the two groups regarding Haemoglobin A1C $(p=0.415)$, Haemoglobin $(p=0.208)$, and total leucocytic count $(\mathrm{p}=0.310)$. But there was statistical significant difference between the two groups regarding platelet count $(\mathrm{p}=0.022)$.

There were no statistical significant differences between the two groups regarding Serum albumin $(\mathrm{p}=0.851)$, Prothrombin activity $(\mathrm{p}=0.356), \operatorname{ESR}(\mathrm{p}=0.805)$, TSH $(\mathrm{p}=$ $0.325)$, and $\alpha$ Feto protein $(p=0.349)$.

There were no statistical significant differences between the two groups regarding abdominal ultrasonography $(\mathrm{p}=0.210)$ and upper GI endoscopy $(\mathrm{p}=1.000)$.

There were statistical significant differences between the two groups regarding SGOT, SGPT and Alkaline phosphatase (Table 1).

There was no statistical significant difference between the two groups regarding indirect bilirubin but there were statistical significant differences between the two groups regarding direct and total bilirubin (Table 2). Chronic hepatitis $\mathrm{C}$ virus (HCV) infection remains a global health threat with the highest prevalence reported in Egypt (Tawhida et al., 2015). In the past few years, a new entity of $\mathrm{HCV}$ infection was identified and defined as occult HCV infection (OCI) which is identified by the presence of HCV RNA in the liver cells or peripheral blood mononuclear cells (PBMCs) of the patients whose serum samples test negative for HCV RNA by polymerase chain reaction (PCR) assays, with or without presence of $\mathrm{HCV}$ antibodies (Carreno et al., 2006).

OCI has been defined in two different forms: cryptogenic and secondary. Cryptogenic OCI: if the patient has no anti-HCV antibodies but has elevated liver enzymes (Castillo et al., 2004). Secondary OCI: if the patient has anti$\mathrm{HCV}$ antibodies, has normal liver enzymes and had cleared his HCV infection either spontaneously or after anti $\mathrm{HCV}$ therapy (Pham et al., 2004).

In our study, HCV RNA was detected in PBMCs of 10out of 40 (25\%) chronic HCV patients treated with the combination of sofosbuvir and daclatasvir for 3 months. As we mentioned before, although the detection of HCV RNA in liver biopsy specimens is the gold standard method for diagnosis of OCI, the detection of HCV RNA in PBMCs is an alternative method in the absence of liver biopsy. HCV RNA was detected in the PBMCs of about $70 \%$ of patients with occult infection. Therefore, detection of HCV RNA in PBMCs does not detect all OCI cases (Carreno et al., 2004).

Previous studies showed that the age (22-66 years) is the common age of OCI. Our study agreed with that, although we detected OCI in old patients above 66 years. This, together with the fact that male sex is predominant in OCI than female sex which is accordant with previous studies by L'opez-Alcorocho and Castillo et al., (L'opez-Alcorocho et al., 2007; Castillo et al., 2007). 
Table.1 Comparison between the two studied groups according to liver enzymes

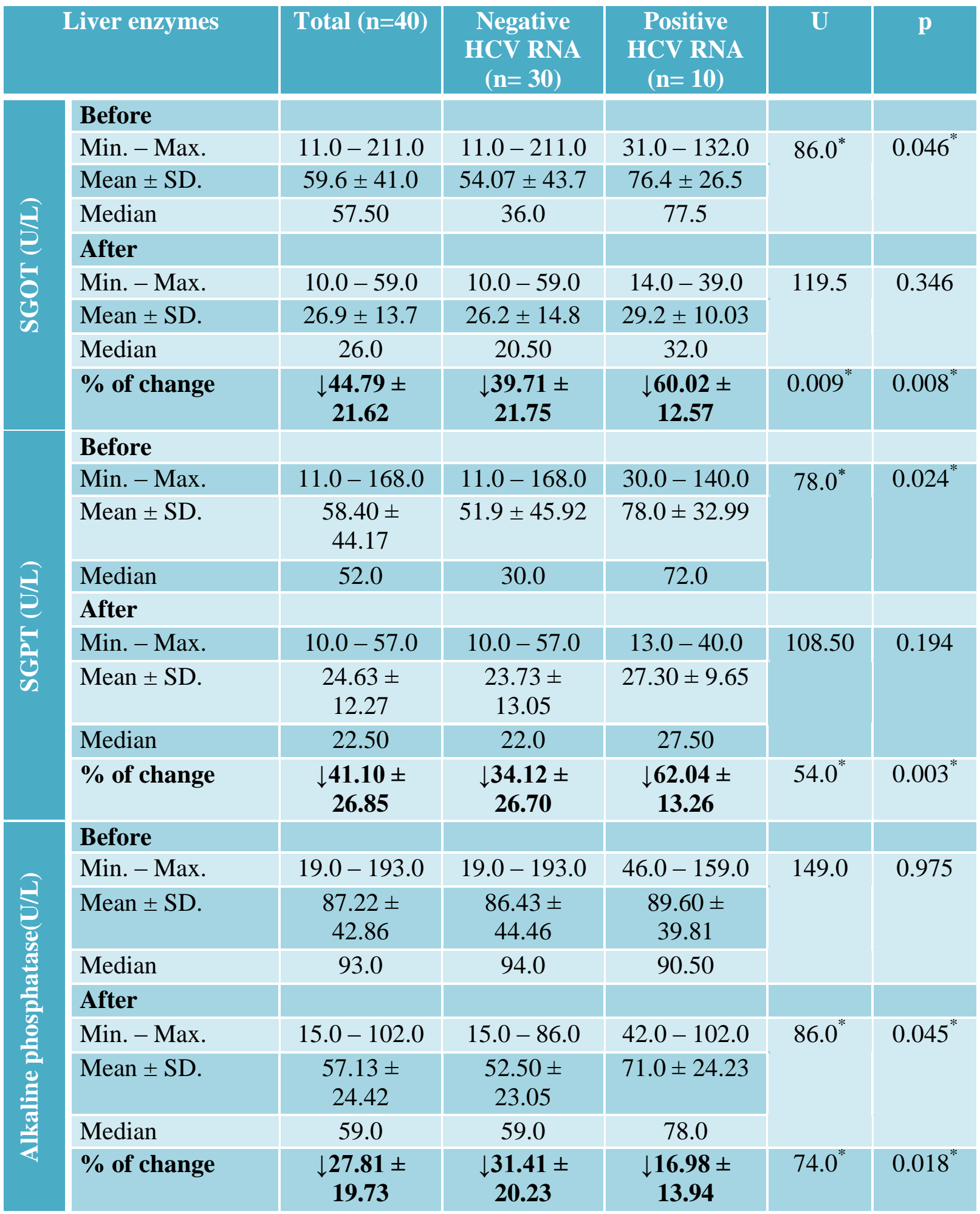

$\mathrm{U}, \mathrm{p}$ : $\mathrm{U}$ and $\mathrm{p}$ values for Mann Whitney test for comparing between the two groups,

*: Statistically significant at $\mathrm{p} \leq 0.05$.

$\mathrm{SGOT}=$ serum glutamate-oxaloacetate transaminase, $\mathrm{SGPT}=$ serum glutamate-pyruvate transaminase, $\mathrm{HCV}$ RNA= Hepatitis $\mathrm{C}$ virus ribonucleic acid. 
Table.2 Comparison between the two studied groups according to bilirubin

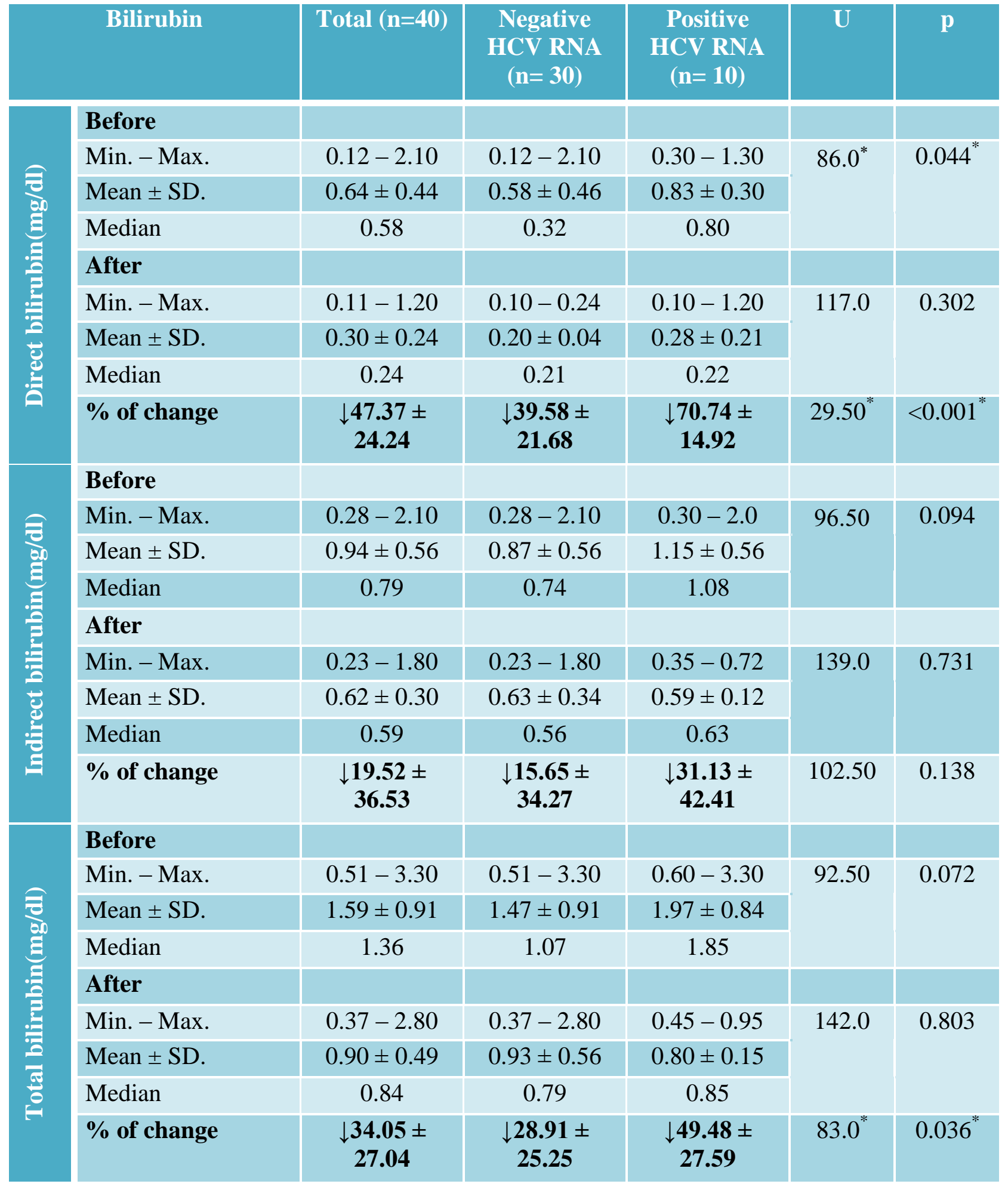

$\mathrm{U}, \mathrm{p}$ : $\mathrm{U}$ and $\mathrm{p}$ values for Mann Whitney test for comparing between the two groups *: Statistically significant at $\mathrm{p} \leq 0.05$

$\mathrm{HCV}$ RNA= Hepatitis C virus ribonucleic acid 
Several Egyptian studies were conducted to detect the prevalence of occult $\mathrm{HCV}$ in different groups of patients, such as in healthy spouses of HCV patients (El Shazly et al., 2015), in patients with chronic lymphoproliferative disorders (Youssef et al., 2012), also in patients with nonalcoholic fatty liver disease (Saad et al., 2011), and hemodialysis patients (Abdelrahim et al., 2016).

Previous study indicated that sexual contact (El Shazly et al., 2015) is one of the most common causes of transmission of OCI. However, in our study, OCI was mainly transmitted by surgery and dental procedures.

In our study, we found that there were statistical significant differences between the two groups regarding liver enzymes as SGOT and SGPT before treatment and in the percent of change (between before and after treatment) as we found that the percent of change decreased significantly in positive group which can be explained by increase rates of liver enzymes significantly before treatment in positive group, while in serum alkaline phosphatase we found that there were statistical significant differences between the two groups after treatment and in the percent of change. Other previous studies revealed an insignificant difference in the prevalence of occult HCV infection between patients with normal or high liver enzymes results (Saad et al., 2011).

Also, we found that there were statistical significant differences between the two groups regarding direct bilirubin before treatment and in the percent of change as we found that the percent of change decreased significantly in positive group which can be explained by increase rates of direct bilirubin significantly before treatment in positive group, while in total bilirubin we found that there were statistical significant differences between the two groups only in the percent of change, also we found that there was no statistical significant difference between the two groups regarding indirect bilirubin.

In conclusion, this study is the first Egyptian study to investigate the prevalence of occult $\mathrm{HCV}$ in patients with secondary OCI who had cleared his HCV infection after anti HCV therapy with the combination of sofosbuvir and daclatasvir for 3 months. Despite this, the present study had some limitations, such as absence of confirmed OCI in liver tissue and small sample size. Therefore, further studies with larger sample are recommended and also we recommend some studies be performed to investigate the prevalence of secondary OCI after therapy with new regimens.

\section{Acknowledgement}

We are grateful to all the patients for providing us blood samples for research. We are also very grateful to Dr. Ahmed Kamal and Dr. Amr Salamah for helping in sample collection and data recording of patients.

\section{References}

Abdelrahim SS, Khairy R, Esmail MA, et al., 2016. Occult hepatitis C virus among Egyptian hemodialysis patients. J Med Virol.

Abdel-Razek W, Waked I. 2015. Optimal therapy in genotype 4 chronic hepatitis C: finally cured? Liver Int Jan., 35 Suppl. 1: 27-34.

Bartolome, J., Lopez-Alcorocho, J.M., Castillo, I., et al., 2007. Ultracentrifugation of serum samples allows detection of hepatitis $\mathrm{C}$ virus RNA in patients with occult hepatitis C. J Virol, 81(14): 7710-7715.

Bertino G, Ardiri A, Proiti M., et al., 2016. Chronic hepatitis $\mathrm{C}$ : This and the new era of treatment. World J Hepatol Jan 
18(2): 92-106.

$\mathrm{C}$ virus (HCV) and occult $\mathrm{HBV}$ and $\mathrm{HCV}$ dual infection, Journal of Medical Virology., 79(3): 236-241.

Carreno V, Bartolome J, Castillo I., et al., 2012. New perspectives in occult hepatitis C virus infection. World J Gastroenterol, 18(23): 2887-94.

Carreno, V., Castillo, I., Bartolome, J., et al., 2004. Comparison of hepatitis $\mathrm{C}$ virus RNA detection in plasma, whole blood and peripheral blood mononuclear cells of patients with occult hepatitis $\mathrm{C}$ virus infection. J Clin Virol, 31(4): 312- 313.

Carreno, V., Pardo, M., Lopez-Alcorocho, J.M., et al., 2006. Detection of hepatitis $\mathrm{C}$ virus (HCV) RNA in the liver of healthy, anti- HCV antibody-positive, serum HCV RNA-negative patients with normal alanine aminotransferase levels. J Infect Dis, 194(1): 53-60.

Castillo I, Rodr'1guez-Irnigo, E, L'opezAlcorocho, J. M., et al., 2007. "Comparative study on the clinical and virological characteristics among patients with single occult hepatitis B virus (HBV), single occult hepatitis.

Castillo, I, Pardo, M., Bartolome, J et al., 2004. Occult hepatitis $C$ virus infection in patients in whom the etiology of persistently abnormal results of liverfunction tests is unknown. $J$ Infect. Dis., 189(1): 7-14.

Chen SL, Morgan TR. 2006. The natural history of hepatitis $\mathrm{C}$ virus (HCV) infection. Int J Med Sci., 3(2): 47-52.

El Shazly Y, Hemida K, Rafik M., et al., 2015. Detection of occult hepatitis C virus among healthy spouses of patients with HCV infection. J Med Virol., 87: 424-427.

Fusun Comert, Elif Aktas, H. Agah Terzi., et al., 2013. Evaluation of hepatitis C virus RNA stability in room temperature and multiple freeze-thaw cycles by COBAS AmpliPrep/COBAS
TaqMan HCV. Diagnostic Microbiology and Infectious Disease 75: 81-85.

Kirkpatrick LA, Feeney BC. 2013. A simple guide to IBM SPSS statistics for version 20.0. Student ed. Belmont, Calif.: Wadsworth, Cengage Learning.

Kotz S, Balakrishnan N, Read C.B., et al., 2006. Encyclopedia of statistical sciences. 2nd edn. Hoboken, N.J. Wiley-Interscience.

L'opez-Alcorocho, J. M. Rodr'1guez-Ĩnigo, E. Castillo, I., et al., 2007. The role of genomic and antigenomic HCV-RNA strands as predictive factors of response to pegylated interferon plus ribavirin therapy. Alimentary Pharmacology and Therapeutics, 25(10): 1193-1201.

Pham, T.N., Mac Parland, S.A., Mulrooney, P.M., et al., 2004. Hepatitis C virus persistence after spontaneous or treatment-induced resolution of hepatitis C. J Virol., 78(11): 5867-5874.

Pol S, Corouge M, Vallet-Pichard A. 2016. Daclatasvir-sofosbuvir combination therapy with or without ribavirin for hepatitis $\mathrm{C}$ virus infection: from the clinical trials to real life. Hepatic Medicine: Evidence and Research, 8: 21-6.

Rezaee-Zavareh MS, Einollahi B. 2014. Treatment of occult hepatitis $\mathrm{C}$ virus infection: does it need special attention? Hepat Mon., 14(7): e16665.

Saad Y, Zakaria S, Ramzy I, et al., 2011. Prevalence of occult hepatitis $\mathrm{C}$ in Egyptian patients with non-alcoholic fatty liver disease. Open J Intern Med., 1: 33-37.

Tawhida Y Abdel-Ghaffar, Mostafa M Sira, Suzan El Naghi. 2015. Hepatitis C genotype 4: The past, present, and future. World J Hepatol., 7(28): 27922810.

Yang SS, Kao JH. 2016. Daclatasvircontaining all-oral regimens for the 
treatment of hepatitis $\mathrm{C}$ virus infection. Hepatol. Int. Mar., 10(2):258-66.

Youssef SS, Nasr AS, El Zanaty T., et al., 2012. Prevalence of occult hepatitis $C$ virus in Egyptian patients with chronic lymphoproliferative disorders. Hepatitis
Research and Treatment, Pp. 1-6.

Zaltron S, Spinetti A, Biasi L., et al., 2012. Chronic HCV infection: epidemiological and clinical relevance. BMC Infect Dis., 12 Suppl 2: S2.

\section{How to cite this article:}

Nashwa A. Abu Khadr, Hanan H. Nouh, Nesrine F. Hanafi, Sara L. Asser and Yousra A. Hussain. 2018. Secondary Occult Hepatitis C Virus Infection (HCV) in Chronic HCV Patients after Treatment with Sofosbuvir and Daclatasvir. Int.J.Curr.Microbiol.App.Sci. 7(01): 13571365. doi: https://doi.org/10.20546/ijcmas.2018.701.165 